\title{
North West Division Trainees Day
}

\section{Craufurd, I. A. Davidson and N. Simpson, Trainee Representatives, North West Division}

The 1984 North West Division Trainees Day took place at Prestwich Hospital on 29 February 1984. This was the first occasion on which it was held at a peripheral hospital.

Dr A. A. Campbell (Chairman, NW Division) welcomed trainees to the meeting. He outlined the current programme of the division and encouraged greater trainee participation. This was followed by an explanation of the structure and function of trainee representation, both centrally and locally, from Dr N. Simpson (Honorary Secretary, CTC), who also included a brief report on activities in the past year.

Dr S. D. Soni (Clinical Tutor, Prestwich Hospital) gave a stimulating and informative talk on career prospects in psychiatry for overseas graduates. He emphasized the need for all trainees to ensure that they examine their options thoroughly, make positive career choices and are prepared actively to seek advice and teaching.

The morning session was brought to a close by $\mathrm{Dr} \mathrm{D}$. Allen (Manchester Business School) who talked about recent changes in the management of the NHS. He led us gently through the complex twists of policy in recent years, ending with current developments such as the Griffiths Report and CASPE (Clinical Accountability, Service Planning and Evaluation).

After lunch we split into three groups, one to discuss each of the lectures and the third for the ever popular exam workshop-organized this year by Dr G. McGrath (Lecturer) and Dr. F. Creed (Senior Lecturer, Manchester University).

The second half of the afternoon was taken up with a plenary session comprising reports from the discussion groups and further debate. A variety of points were raised in the various sessions, notably the following topics which secured general agreement.

Overseas graduates need more information on training and prospects, especially before leaving their home countries, but also once they arrived in the UK. Graduates arriving with clear goals and a greater understanding of likely difficulties were considered more likely to be able to progress satisfactorily. Psychiatric tutors could have an important role to play, especially during the trainee's first few months in the UK. Many overseas graduates have little undergraduate experience of psychiatry, are used to more formalized teaching methods, and with the difficulties of initial cultural and language adjustment they are often in need of extra encouragement to participate actively in seeking training. In peripheral hospitals, with trainees and consultants having to cope with heavy service loads, it is especially necessary to be vigilant to avoid training needs and opportunities passing unnoticed.

University postgraduate courses appear to be geared solely to the needs of British graduates, despite the often large proportion of overseas graduates attending. The requirement of doing the PLAB exam in the UK is onerous in that it entails a heavy financial outlay by the candidates in coming to the UK and supporting themselves whilst here. It ought to be possible for candidates to sit it in their home country, providing adequate safeguards could be ensured.

Concern was expressed that with the increasing move to fixed length rotational training schemes the standard threeyear duration was too short. This length, if rigorously enforced, would leave many people seeking new posts or unemployed in the few months prior to sitting the Membership exam. This problem is easily avoided by making rotations of four years' duration, subject to satisfactory progress.

The lecture and ensuing discussion on the NHS management showed that most trainees felt ill-informed and found it hard to come to terms with this topic. It was felt that the Griffiths Report offered little supporting evidence for its proposals. CASPE and similar schemes were considered to have benefits in making clinicians more aware of the nature of the constraints within which the service operates. Discussion of other health care delivery systems supported the idea that the NHS is at present a relatively efficient method of equitably rationing finite resources. Trainees believe that it is important for them to have some training in management structures and financial operations before reaching consultant status. It was suggested that this might best be provided in the form of regular updates throughout the training period. The most appropriate format would need further consideration and the College should concern itself with this aspect of training.

We were pleased to see that the move of venue to a peripheral hospital was successful. The meeting had a good turnout from both regions and from both teaching and peripheral hospitals. It was interesting to note that we obtained a higher proportion of trainees from peripheral units than in previous years. It was disappointing, however, that for a variety of reasons very few tutors were able to attend and we look forward to a higher turnout in future years. We would like to thank all those who helped to make the day such a success.
The following prizes have been awarded for 1984: Gaskell Medal and Prize-awarded jointly to Dr C. L. E. Katona (St George's Hospital Medical School) and Dr R. R.

\section{College Prizes}

Jacobson (Maudsley Hospital).

Bronze Medal and Research Prize-Dr H. M. D. Gurling (Institute of Psychiatry). 